\title{
Catalytic hydrogen production by ruthenium complexes from the conversion of primary amines to nitriles: Potential application as liquid organic hydrogen carrier
}

\begin{abstract}
The potential application of the primary amine/nitrile pair as a liquid organic hydrogen carrier (LOHC) is evaluated. Ruthenium complexes of formula $\left[(p-c y m) R u(N H C)(C l)_{2}\right]$ catalyze the acceptorless dehydrogenation of primary amines to nitriles with the formation of molecular hydrogen. Notably, the reaction proceeds without any external additive, under air, and under mild reaction conditions. The catalytic properties of a ruthenium complex supported on the surface of graphene have been explored for reutilization purposes. The ruthenium-supported catalyst is active for at least ten runs without any apparent loss of activity. The results obtained in terms of catalytic activity, stability, and recyclability are encouraging for the potential application of the amine/nitrile pair as a LOHC. The main challenge in the dehydrogenation of benzyl amines is the selectivity control, such as avoiding the formation of imine by-products due to transamination reactions. Here, selectivity has been achieved by using long-chain primary amines such as dodecyl amine. Mechanistic studies have been performed to rationalize the key factors involved in the activity and selectivity of the catalysts in the dehydrogenation of amines. The experimental results suggest that the catalyst resting state contains a coordinated amine.
\end{abstract}

David Ventura-Espinosa ${ }^{[a]}$, Aida Marzá-Beltrán ${ }^{[a]}$ and Jose A. Mata*[a]

\section{Introduction}

The use of molecular hydrogen as an alternative energy source is a highly desirable process. ${ }^{[1-3]}$ The key is the production of energy with the formation of water as the only by-product. From the environmental and sustainable points of view, the advantages versus other technologies are notorious. ${ }^{[4-6]}$ Nevertheless, there are still some limitations to overcome that should be addressed by technological and scientific approaches: i)hydrogen production and ii)hydrogen storage. ${ }^{[7-9]}$ The production of hydrogen is wellknown, the problem arises from the bulk production. In an ideal situation, industrial hydrogen production would require the use of renewable energy sources to obtain hydrogen from the electrolysis of water. Many efforts have pursued this goal and the achievements in the lasts years are considerable. ${ }^{[10,11]}$ The success of hydrogen as an alternative energy source relies on the development of efficient hydrogen storage and transport systems. ${ }^{[12-14]}$ Nowadays, hydrogen storage represents a technological challenge. ${ }^{[15,16]}$ Among all the possibilities, chemical

[a] D. Ventura-Espinosa, A. Marzá-Beltrán and J. A. Mata* Institute of Advanced Materials (INAM)

Universitat Jaume I

Avda. Sos Baynat s/n, 12006, Castellón (Spain)

E-mail: jmata@uji.es

Supporting information for this article is given via a link at the end of the document. hydrogen storage in the form of organic liquids represents an attractive route for the development of hydrogen carrier systems. ${ }^{[17-20]}$ In this sense, the technological problems are minimized as the actual infrastructure is based in liquids for storage and transport. ${ }^{[21,22]}$ The future of liquid organic hydrogen carriers (LOHC) depends on a reversible chemical reaction based on the release and uptake of hydrogen. ${ }^{[23-27]}$ In this work, we have evaluated the potential of the amine/nitrile pair as a liquid organic hydrogen carrier, as suggested by Grellier and Sabo-Etienne in a frontier type article (Scheme 1). ${ }^{[28]}$

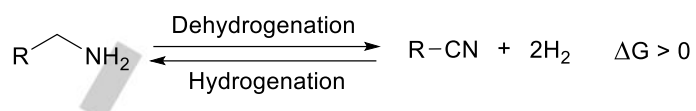

Scheme 1. (De)hydrogenation of the amine/nitrile pair.

The acceptorless dehydrogenation of primary amines generates the corresponding nitrile and two moles of hydrogen. The reaction is not favored at room temperature and an effective catalyst is needed for practical purposes. Efficient catalysts for the acceptorless dehydrogenation of amines are scarce and were first developed by the group of Szymczak based on a ruthenium pincer complex. ${ }^{[29]}$ The viability of the amine/nitrile pair as a potential organic hydrogen carrier also lies in the effectiveness of the reverse process, this is, the hydrogenation of nitriles. Fortunately, the hydrogenation of nitriles is a well-documented catalytic reaction and efficient catalysts have been described in the literature. ${ }^{[30-35]}$ Nitriles are versatile intermediates in organic synthesis owing to their direct conversion into a variety of functional groups. Conventional organic procedures require nucleophilic displacement of suitable leaving groups producing stoichiometric amounts of waste and with limited selectivity. ${ }^{[36,37]}$ A novel and green method for the synthesis of nitriles consists in the acceptorless dehydrogenation of primary amines. This method does not require the use of stoichiometric oxidants and the only by-product is molecular hydrogen.

In this work, we describe the production of hydrogen from primary amines using ruthenium catalysts, showing the potential application of the primary amine/nitrile pair as a liquid organic hydrogen carrier. Studies on the catalytic activity and selectivity allow us to propose a plausible mechanism for the dehydrogenation of amines.

\section{Results and Discussion}

Synthesis of ruthenium complexes. A series of ruthenium complexes $(\mathbf{2 a}-\mathbf{2 c})$ were obtained in good yield from the 
corresponding imidazolium salts (1a - 1c) by transmetallation using silver oxide (Scheme 2). The complexes were fully characterized by nuclear magnetic resonance, electrospray mass ionization, and elemental analysis. The ruthenium complexes ${ }^{[38-}$ 40] differ in the substituents at the 4 and 5 positions of the $\mathrm{N}$ heterocyclic carbene ligand (NHC). Fine-tuning of the electronic properties of the $\mathrm{NHC}$ ligands is achieved by introduction of electron donating $\left(-\mathrm{CH}_{3}\right)$ or electron withdrawing groups $(-\mathrm{Cl}) \cdot{ }^{[41]}$ Modifying the substituents at the backbone of the azol ring does not alter significantly the steric properties of the NHC ligands, which are controlled by the substituents at the nitrogen positions 1 and 3 (n-butyl groups). ${ }^{[42,43]}$

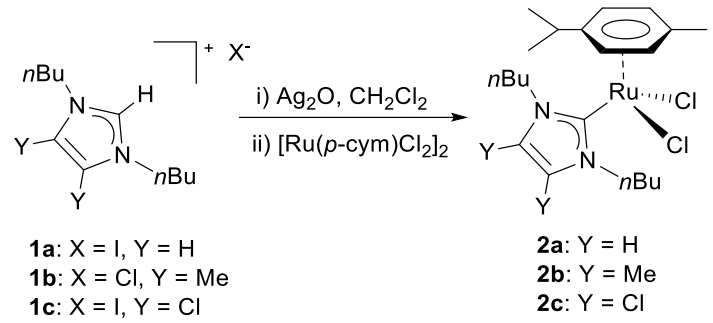

Scheme 2. Synthesis of ruthenium complexes.

Catalytic properties. In a first set of experiments, the dehydrogenation of benzyl amine was chosen as the model reaction for the optimization of the reaction conditions (Table 1 ). One equivalent of benzyl amine and $2 \mathrm{~mol} \%$ of catalyst were dissolved in $3 \mathrm{~mL}$ of solvent and heated at vigorous reflux. A control experiment showed that the dehydrogenation reaction did not proceed in the absence of catalyst (Entry 1). When the reaction was carried out in the presence of a halide abstractor additive, benzyl amine was converted to an equimolar mixture of nitrile and imine (Table 1, entry 2). The use of different bases slightly increased the selectivity towards the nitrile compound without altering the conversion, except in the case of $t \mathrm{BuOK}$. The use of such a strong base was detrimental for the dehydrogenation of benzyl amine and only $34 \%$ conversion was reached (Table 1, entries $3-5$ ). The best results were achieved in the absence of any external additive (Table 1, entries $6-8$ ). The reaction of benzyl amine with catalyst $2 \mathbf{a}$ in toluene without any additive afforded full conversion after $8 \mathrm{~h}$. The reaction selectivity favoured the formation of the nitrile product. The ruthenium catalysts $\mathbf{2 a}-\mathbf{2 c}$ with different electronic properties displayed no significant difference in terms of catalytic activity or product selectivity. We observed that the selectivity in the dehydrogenation of amines was largely dependent on the reaction conditions. When the reaction of benzyl amine using catalysts $2 a-2 c$ was carried out in a closed vessel, the only product formed was the imine (the acceptorless dehydrogenative coupling or transamination product). The homocoupling of primary amines using catalyst $\mathbf{2} \mathbf{a}$ has previously been described in a closed system showing the sole formation of the imine product. ${ }^{[4]}$ The dehydrogenation of amines is a nonspontaneous thermodynamic process. The release of hydrogen from the reaction media produces an equilibrium shift towards product formation. We thus conclude that vigorous refluxing conditions favor the reaction by facilitating the release of hydrogen. When the reaction is carried out with intense solvent bubbling, the conversion is increased. Solvent optimization was carried out for catalyst 2c (Table 1, entries $9-13$ ). The best results were obtained using p-methylbenzyl amine as the substrate and toluene as the solvent. The use of acetonitrile or alcohols as the solvent decreased the reaction conversion and selectivity of dehydrogenation. Two different experiments served to evaluate whether oxygen from air is the final oxidant in the dehydrogenation of amines (Entries $14-15$ ). The reaction of benzyl amine was carried out under intense nitrogen bubbling. The results suggest that oxygen is not needed in the dehydrogenation process. Confirmation was obtained when carrying the same experiment under oxygen atmosphere. The presence of oxygen afforded less than $5 \%$ conversion. This result suggests that oxygen is not the final oxidant in the dehydrogenation of amines; in fact, the results suggest that the catalyst is inactive under catalytic conditions in the presence of oxygen.

Table 1. Optimization parameters for the catalytic dehydrogenation of primary amines.

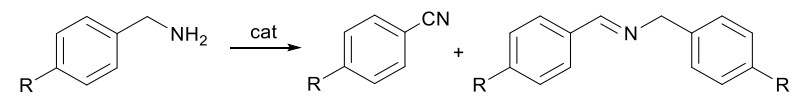

\begin{tabular}{|c|c|c|c|c|c|c|c|}
\hline \multirow[b]{2}{*}{ Entry } & \multirow[b]{2}{*}{ Cat. } & \multirow[b]{2}{*}{$\mathrm{R}$} & \multirow[b]{2}{*}{ Additive } & \multirow[b]{2}{*}{ Solvent } & \multirow[b]{2}{*}{ Conv. $(\%)^{[a]}$} & \multicolumn{2}{|c|}{$\begin{array}{c}\text { Selectivity } \\
(\%)\end{array}$} \\
\hline & & & & & & Nitrile & Imine \\
\hline 1 & - & $\mathrm{H}$ & - & Toluene & 0 & - & - \\
\hline 2 & $2 a$ & $\mathrm{H}$ & AgOTf & Toluene & 92 & 49 & 51 \\
\hline 3 & $2 a$ & $\mathrm{H}$ & tBuOK & Toluene & 34 & 68 & 32 \\
\hline 4 & $2 a$ & $\mathrm{H}$ & $\mathrm{Cs}_{2} \mathrm{CO}_{3}$ & Toluene & 88 & 70 & 30 \\
\hline 5 & $2 a$ & $\mathrm{H}$ & $\mathrm{NaOAc}$ & Toluene & 97 & 60 & 40 \\
\hline 6 & $2 a$ & $\mathrm{H}$ & - & Toluene & 98 & 74 & 26 \\
\hline 7 & $2 b$ & $\mathrm{H}$ & - & Toluene & 95 & 73 & 27 \\
\hline 8 & $2 c$ & $\mathrm{H}$ & - & Toluene & 100 & 75 & 25 \\
\hline 9 & $2 c$ & $\mathrm{CH}_{3}$ & - & Toluene & 100 & 74 & 26 \\
\hline 10 & 2c & $\mathrm{CH}_{3}$ & - & $\mathrm{MeCN}$ & 24 & 50 & 50 \\
\hline 11 & 2c & $\mathrm{CH}_{3}$ & - & iPrOH & 54 & 68 & 32 \\
\hline 12 & 2c & $\mathrm{CH}_{3}$ & - & $\mathrm{tBuOH}$ & 75 & 65 & 35 \\
\hline 13 & 2c & $\mathrm{CH}_{3}$ & - & $\mathrm{nBuOH}$ & 39 & 64 & 36 \\
\hline 14 & 2c & $\mathrm{H}$ & $\mathrm{N}_{2}$ (bubbling) & Toluene & 98 & 71 & 29 \\
\hline 15 & $2 c$ & $\mathrm{H}$ & $\mathrm{O}_{2}(1 \mathrm{~atm})$ & Toluene & $<5$ & n. d. & n. d. \\
\hline
\end{tabular}

Reaction conditions: Substrate $(0.3 \mathrm{mmol})$, catalyst $(2 \mathrm{~mol} \%), 3 \mathrm{~mL}$ of solvent at reflux for $8 \mathrm{~h}$. [a] Conversion determined by GC analysis using anisole as the internal standard. (n. d.; not determined).

The reaction scope and limitations of the catalytic dehydrogenation of benzyl amines were evaluated using complexes $\mathbf{2 c}$ and $\mathbf{3}$ as catalyst precursors (Table 2). The reaction conditions consisted in toluene as the solvent at $110{ }^{\circ} \mathrm{C}$ and a catalyst loading of $2 \mathrm{~mol} \%$. Complex 3 was used for comparative reasons. The immobilization of complex 3 on graphene has been 
previously described and we wanted to assess the catalytic properties of a supported molecular ruthenium catalyst in the dehydrogenation of amines. ${ }^{[45]}$ The evaluation of the catalytic properties revealed that both ruthenium complexes are active in the dehydrogenation of a variety of amines containing different substituents. In all cases, full conversions were achieved in ca. 8 h. Only in the case of bulky amines such as 1-naphtylmethyl amine, the dehydrogenation process was slower (Table 2, entries $12-13)$. The best results in terms of catalytic activity were obtained in the case of benzyl amine using catalyst 2c. A comparative reaction profile was carried out using 4methoxybenzyl amine as a model substrate and complexes 2c and 3 as the catalyst precursors (Figure S1). In general, the differences observed in catalytic activity of complexes $2 \mathrm{c}$ and $\mathbf{3}$ are negligible. The formation of molecular hydrogen was confirmed by injection of the gases released in the reactions described in entries 7 and 8 directly into a gas chromatograph. The challenge in the dehydrogenation of benzyl amines is to control the selectivity of the reaction. In general, it has been found that controlling the factors that govern the formation of the different produts is difficult. The use of ruthenium complexes with different ligands has proved inefficient to control the selectivity and further efforts to design high selective catalyst are thus required. The best results in terms of selectivity were obtained for benzyl amine using complex $\mathbf{3}$ as the catalyst (Table 2, entry 2). The catalytic properties and recycling studies of the hybrid

Table 2. Reaction scope and limitations of the catalytic dehydrogenation of primary amines.

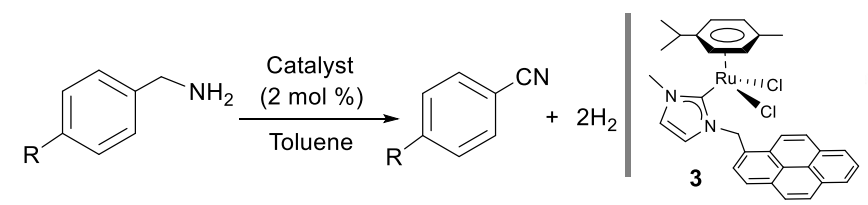

\begin{tabular}{|c|c|c|c|c|c|}
\hline \multirow[t]{2}{*}{ Entry } & \multirow[t]{2}{*}{ Catalyst } & \multirow[t]{2}{*}{$\mathrm{R}$} & \multirow[t]{2}{*}{ Conv.(\%) $)^{[a]}$} & \multicolumn{2}{|c|}{ Selectivity (\%) } \\
\hline & & & & Nitrile & Imine \\
\hline 1 & 2c & $\mathrm{H}$ & 100 & 75 & 25 \\
\hline 2 & 3 & $\mathrm{H}$ & 99 & 82 & 18 \\
\hline 3 & NHC-Ru-rGO (4) & $\mathrm{H}$ & $100^{[b]}$ & 65 & 35 \\
\hline 4 & 2c & $\mathrm{Cl}$ & 95 & 50 & 50 \\
\hline 5 & 3 & $\mathrm{Cl}$ & 83 & 57 & 43 \\
\hline 6 & 2c & $\mathrm{Me}$ & 100 & 74 & 26 \\
\hline 7 & 3 & $\mathrm{Me}$ & 93 & 70 & 30 \\
\hline 8 & 2c & $\mathrm{OMe}$ & 99 & 69 & 31 \\
\hline 9 & 3 & $\mathrm{OMe}$ & 97 & 68 & 32 \\
\hline 10 & 2c & $\mathrm{CF}_{3}$ & 95 & 62 & 38 \\
\hline 11 & 3 & $\mathrm{CF}_{3}$ & 78 & 52 & 48 \\
\hline 12 & 2c & Naphtyl & 80 & 55 & 45 \\
\hline 13 & 3 & Naphtyl & 82 & 57 & 43 \\
\hline
\end{tabular}

Reaction conditions: Substrate $(0.3 \mathrm{mmol})$, catalyst $(2 \mathrm{~mol} \%), 2 \mathrm{~mL}$ of toluene at $110^{\circ} \mathrm{C}$ for $8 \mathrm{~h}$. [a] Conversion determined by GC analysis using anisole as the internal standard. [b] After $6 \mathrm{~h}$ of reaction. material NHC-Ru-rGO (4) were carried out using benzyl amine (Entry 3 and Figure 1). The results show that immobilization of complex 3 on the graphene surface increases the catalytic activity. Full conversion was achieved in $6 \mathrm{~h}$, in contrast to the $8 \mathrm{~h}$ required with molecular complex 3 . These results support our previous catalytic studies using molecular complexes anchored on graphene. ${ }^{[45,46]}$ The immobilization of molecular complexes on graphene by non-covalent interactions shows a catalytic benefit compared to the molecular complexes most probably due to the increase stability of the catalytic active species.

The reaction scope of the catalytic dehydrogenation alkyl primary amines was evaluated (Table 3 ). The results show that the ruthenium complexes $\left[(p\right.$-cym $\left.) \mathrm{Ru}(\mathrm{NHC})(\mathrm{Cl})_{2}\right]$ are active in the dehydrogenation of alkyl amines under the same reaction conditions as described for the benzyl amines. In the case of alkyl amines we observed a better control of the selectivity towards nitrile formation. Increasing the number of carbons of the alkyl chain inhibited the formation of the transamination product. For example, dehydrogenation of heptyl amine yielded $78 \%$ of nitrile product, octyl amine afforded $89 \%$ and, in the case of dodecyl amine the nitrile product was obtained in $100 \%$ yield (Table 3 , entries $1-3)$. The formation of the transamination product is thus inhibited for long-chain alkyl amines. In the case of tetradecyl amine, hexadecyl amine and octadecyl amine, the only product observed was the nitrile compound. The use of long-chain alkyl amines to control the selectivity in the oxidation of primary amines has recently been described. ${ }^{[47]}$ Control over the selectivity is an important issue when considering the amine/nitrile pair as a promising candidate for LOHC. It has been described that $\mathrm{N}$ heterocycles are considered good LOHCs and control of the selectivity can be easily achieved. For comparative purposes, we studied the activity of the ruthenium complexes in the dehydrogenation of indoline (Scheme 3). The ruthenium complexes 2c and 3 catalyzed the dehydrogenation of indoline quantitatively in $6 \mathrm{~h}$ at $110^{\circ} \mathrm{C}$.

Table 3. Dehydrogenation of alkyl primary amines.

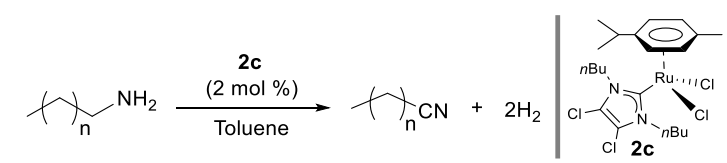

\begin{tabular}{cccccc}
\hline Entry & Amine & $\mathrm{n}$ & Conv. (\%) [a] $^{[}$ & \multicolumn{2}{c}{ Selectivity (\%) } \\
& & & & Nitrile & Imine \\
\hline 1 & Heptyl amine & 5 & 95 & 78 & 22 \\
2 & Octyl amine & 6 & 99 & 89 & 11 \\
3 & Dodecyl amine & 10 & 100 & 100 & 0 \\
4 & Tetradecyl amine & 12 & 95 & 100 & 0 \\
5 & Hexadecyl amine & 14 & 97 & 100 & 0 \\
6 & Octadecyl amine & 16 & 95 & 100 & 0 \\
\hline
\end{tabular}

Reaction conditions: Substrate $(0.3 \mathrm{mmol})$, catalyst $(2 \mathrm{~mol} \%), 2 \mathrm{~mL}$ of toluene at $110^{\circ} \mathrm{C}$ for $24 \mathrm{~h}$. [a] Conversion determined by GC analysis using anisole as the internal standard. 


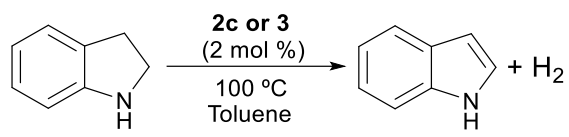

Yield: 2c, $100 \%$

3, $100 \%$

Scheme 3. Dehydrogenation of indoline.

Recycling studies. We have recently described a methodology for obtaining supported catalyst onto the surface of graphene by means of non-covalent interactions. ${ }^{[45,46]}$ The catalytic properties of the hybrid materials in terms of activity and stability have demonstrated the potential of transition metals immobilized on graphene. ${ }^{[48-50]}$ The catalytic results improve when the metal complexes are anchored on graphene and the hybrid materials can be recycled up to ten times due to their enhanced stability. In view of the good results obtained, we decided to assess the catalytic activity of a similar ruthenium-based hybrid material derived from complex $\mathbf{3}$ in the hydrogen production from primary amine dehydrogenation (Scheme 4).
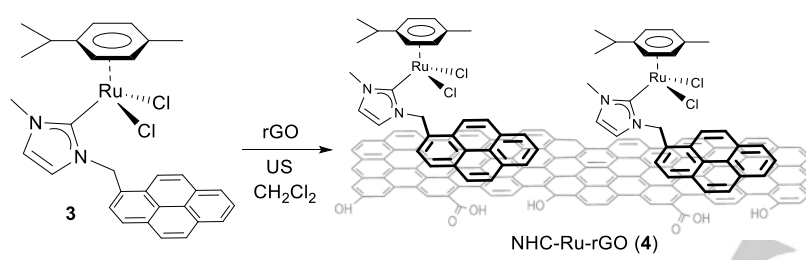

Scheme 4. Synthesis of the hybrid material NHC-Ru-rGO (4).

The catalytic properties of molecular complex 3 and its derived hybrid material 4 were analyzed under the same reaction conditions (Table 2 , entries $2-3$ ). The results show that the catalytic activity of the molecular complex is maintained after immobilization. In general, one of the drawbacks of supported molecular catalysis is the decrease in the reaction rate due to diffusion problems. The catalytic activity of $\mathbf{3}$ was not altered after immobilization on graphene most probably because of the $2 \mathrm{D}$ character of graphene that facilitates the accessibility to all catalytic active centers. The same behaviour has been previously observed when comparing the catalytic activity of other molecular complexes and their corresponding immobilized hybrid materials. ${ }^{[45]}$

Recycling experiments were carried out using benzyl amine as the model substrate. The reactions were performed using a catalyst loading of $2 \mathrm{~mol} \%$ (based on ruthenium), and $3 \mathrm{~mL}$ of toluene at $110^{\circ} \mathrm{C}$. The reaction profile for each run was monitored by GC until a maximum of ca. $50 \%$ conversion. After each run, the mixture was allowed to cool down to room temperature, and the solid catalyst was separated by decantation, washed thoroughly with toluene, and used in the next run (Figure 1).

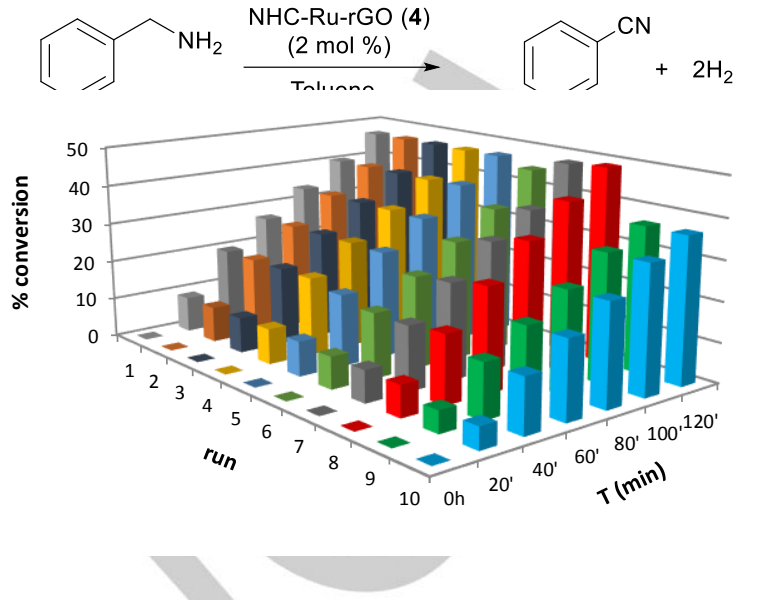

Figure 1. Recycling experiments on the dehydrogenation of benzyl amine using the hybrid material NHC-Ru-rGO (4). Reaction profile for each run determined by $\mathrm{GC}$ analysis at a maximum of ca. $50 \%$ conversion.

The hybrid material NHC-Ru-rGO (4) was reused up to ten times without any significant decrease in activity. There is a slight decrease of the catalytic activity in run 9 that is maintained in run 10. The reaction profile for each run allows comparison of the catalytic activity for different reaction times. The results show that the catalytic activity is maintained for the different runs. The morphology of the catalytic hybrid material NHC-Ru-rGO (4) was analyzed by HRTEM after the recycling experiments. Comparison of the images before and after the recycling experiments reveal a well-dispersed ruthenium distribution without the presence of metal nanoparticles (Figure 2). The morphology of graphene does not display significant changes apart from an increase in the number of wrinkles.
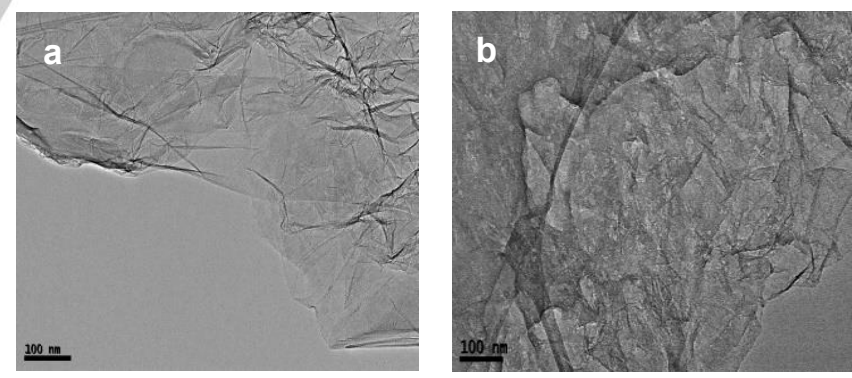

Figure 2. HRTEM images of PhF-Ru-rGO (4) before (a) and after (b) ten catalytic runs.

In order to stablish the mode of action of the hybrid material NHCRu-rGO (4) during catalysis, a hot filtration experiment was carried out. This experiment rules out the possibility of releaseand-return of the molecular complex from the surface of graphene. 
If the molecular complex is retained on the surface of graphene, the catalysis is heterogeneous in nature, however, if the molecular complex is released, the catalysis is homogeneous. The hot filtration experiment was carried out using NHC-Ru-rGO (4) (2 $\mathrm{mol} \%)$ as the catalyst and benzyl amine as the substrate. The catalytic hybrid material NHC-Ru-rGO (4) was removed from the reaction medium by filtration at high temperature $\left(110^{\circ} \mathrm{C}\right)$ when the conversion reached $50 \%$ (ca. $2 \mathrm{~h}$ ). The filtrate was stirred for $2 \mathrm{~h}$ more under identical conditions. After this time, the GC analysis indicated that no further amine dehydrogenation had occurred (GC conversion remained at $50 \%$ ). The catalytic hybrid material NHC-Ru-rGO (4), previously removed from the reaction medium, was then treated with more benzyl amine. After $2 \mathrm{~h}$ at $110^{\circ} \mathrm{C}$, we observed that the reaction had proceed, indicating that the hybrid material NHC-Ru-rGO (4) was still active. The hot filtration experiment confirmed the absence of catalytic species in solution due to catalyst desorption from the graphene surface and demonstrated the heterogeneous nature of the catalytic process. The recycling properties of hybrid material NHC-Ru-rGO (4) are excellent and most probably due to the stabilization of molecular ruthenium complex 3 on the surface of graphene.

Mechanistic considerations. Preliminary studies for the mechanism in the acceptorless dehydrogenation of amines were performed by monitoring the reaction profile by ${ }^{1} \mathrm{H}$ NMR spectroscopy (Figure 3). The catalytic dehydrogenation of $p$ methoxybenzyl amine was carried out using complex 2c in deuterated toluene. The results show that signals corresponding to the nitrile product start to appear after $2 \mathrm{~h}$, suggesting that dehydrogenation towards nitrile is fast. However, the reaction needed four days to achieve full conversion. In general, the kinetics of catalytic reactions carried out in NMR tubes is slow due to diffusion problems. We have observed that the reaction conditions have an important influence in the kinetics in regard to the facile release of hydrogen. The reaction is slowed down when there is not a vigorous bubbling as it happens in the NMR tube. Importantly, the only products observed during all the catalytic reaction are the nitrile and imine, no other products were detected. In general, it should be possible to detect the presence of dissolved molecular hydrogen by ${ }^{1} \mathrm{H}$ NMR spectroscopy. In our case, we did not observed the formation of molecular hydrogen. Most probably, hydrogen needs to be released for reaction evolution. In order to confirm the presence of hydrogen, a similar experiment was carried out using a sacrificial hydrogen acceptor. The reaction was carried out with benzyl amine, complex $2 c$ and two equivalents of t-butyl ethylene (tbe) in deuterated toluene. The ${ }^{1} \mathrm{H}$ NMR recorded after the experiment showed the formation of products but no ethylene hydrogenation. This result suggests that our ruthenium complex is a poor hydrogenation catalyst. Further evidence is that the imine product was not hydrogenated to the corresponding amine. The formation of $\mathrm{H}_{2}$ in the dehydrogenation of amines was analyzed in a different experiment by gas chromatography (GC). A solution of complex 2c and benzyl amine in toluene was heated under catalytic conditions. A sample of the generated gas was collected and injected directly into the GC using a gas-syringe. The results confirmed the presence of molecular hydrogen generated from the dehydrogenation of amines.

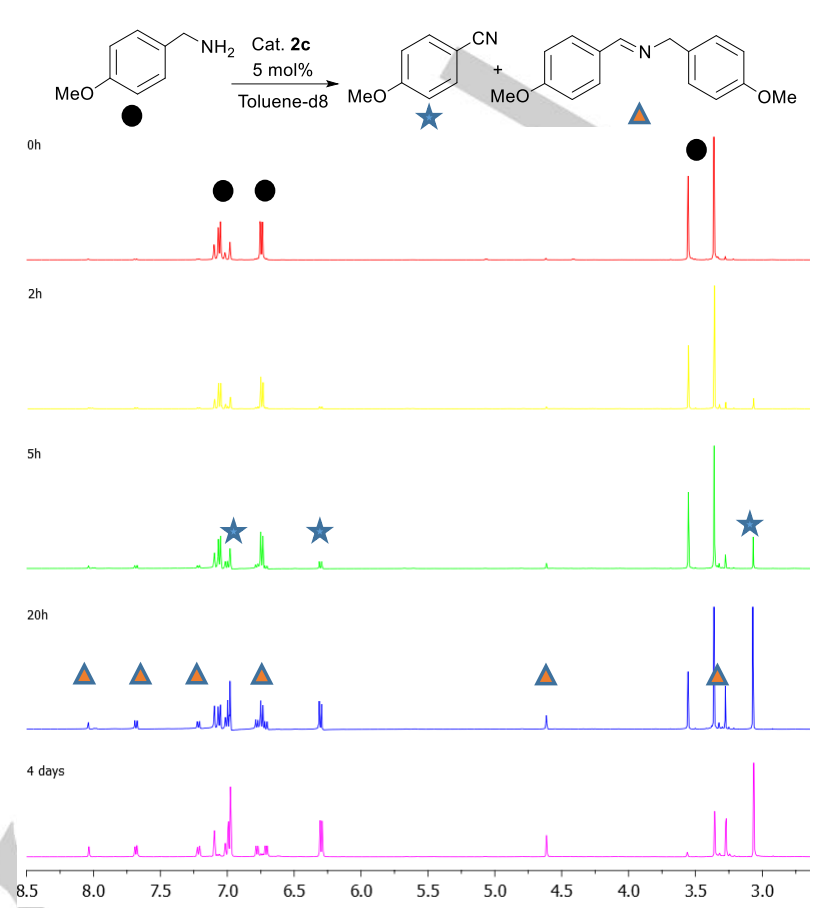

Figure 3. Catalytic dehydrogenation profile of $p$-methoxybenzyl amine using complex 2c in deuterated toluene showing the full conversion and the formation of nitrile and imine products.

Further mechanistic investigations were carried out by singlestage ESI-MS (Figure 4). An equimolar mixture of complex 2c and p-methylbenzyl amine was dissolved in toluene, heated at $70^{\circ} \mathrm{C}$ for $10 \mathrm{~min}$. and analyzed by direct injection into ESI-MS. The results show the presence of two species in solution. The peak at $\mathrm{m} / \mathrm{z}=521.1$ was assigned to complex 2c with a vacant coordination site, formulated as $[\mathrm{M}-\mathrm{Cl}]^{+}$. A second and more intense peak at $\mathrm{m} / \mathrm{z}=642.1$ was assigned to complex 2c which contains a coordinated p-methylbenzyl amine [M$\left.\mathrm{Cl}+\mathrm{H}_{2} \mathrm{NCH}_{2} \mathrm{PhMe}\right]^{+}$. The proposed molecular composition was further confirmed by the simulated isotopic pattern distribution. When the same experiment was reproduced at $110^{\circ} \mathrm{C}$ instead of $70{ }^{\circ} \mathrm{C}$, neither the formation of this reaction intermediate or any other ruthenium species was detected. The results suggests that i) at low temperatures, a chloride ligand in complex $2 \mathrm{c}$ is replaced by a $p$-methylbenzyl amine and ii) at high temperatures, the amine is converted to the nitrile product and no other ruthenium intermediates are detected. These results support that complex 6 is the resting state in the dehydrogenation of amines (vide infra). Metal-halide bond breaking and coordination of an L-type ligand yielding cationic species has previously been reported for ruthenium p-cymene species. ${ }^{[51]}$ A further experiment was performed in order to confirm the coordination of $p$-methylbenzyl amine to ruthenium and discard the possibility that this product is only formed under ESI-MS conditions. Ruthenium complex $\mathbf{5}$ and p-methylbenzyl amine were dissolved in $\mathrm{CH}_{2} \mathrm{Cl}_{2} / \mathrm{MeOH}(3: 2 \mathrm{v} / \mathrm{v})$. Addition of sodium tetrafluoroborate afforded the aminecoordinated product 6 in high yield (Figure 5). Ruthenium complex 6 is stable in solution and in the solid state. The molecular 
structure of complex 6 was confirmed by single crystal X-ray diffraction.

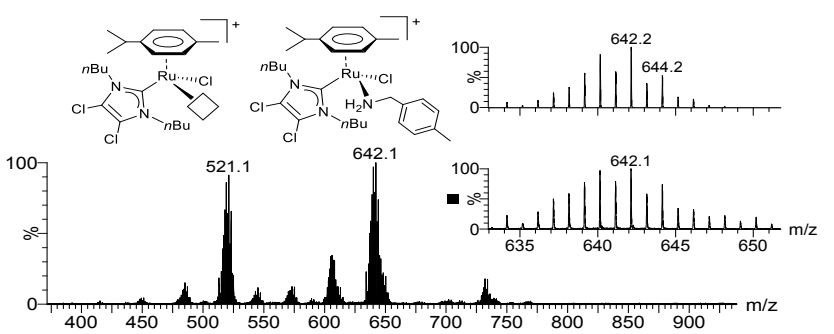

Figure 4. ESI-MS spectrum of complex 2c in the presence of p-methylbenzyl amine under stoichiometric conditions. Schematic drawings of the species detected: i) with a vacant coordination site $[\mathrm{M}-\mathrm{Cl}]^{+}$and ii) with a coordinated $\mathrm{p}$ methylbenzyl amine $\left[\mathrm{M}-\mathrm{Cl}+\mathrm{H}_{2} \mathrm{NCH}_{2} \mathrm{PhMe}\right]^{+}$. Inset: Experimental and simulated isotopic pattern of $\left[\mathrm{M}-\mathrm{Cl}+\mathrm{H}_{2} \mathrm{NCH}_{2} \mathrm{PhMe}\right]^{+}$

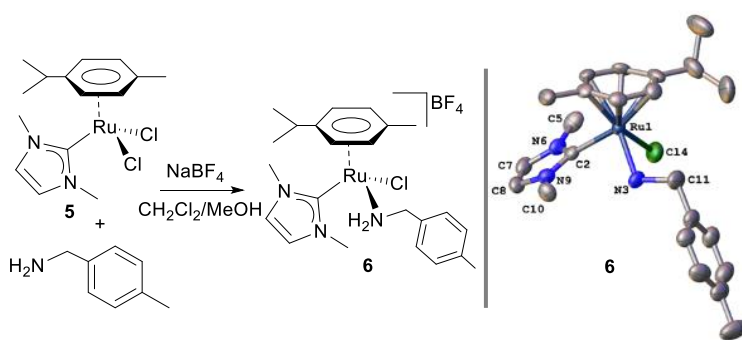

Figure 5. Synthesis and molecular diagram of compound 6. Ellipsoids are at $50 \%$ probability level. Hydrogen atoms and counter anion $\left(\mathrm{BF}_{4}{ }^{-}\right)$have been omitted for clarity.

A mechanism for the dehydrogenation of primary amines is proposed in Figure 6 based on experimental evidences. Mechanistic reports for the dehydrogenation of primary amines are scarce. Brookhart et al. proposed a reaction mechanism for an iridium complex using a hydrogen acceptor. ${ }^{[52]}$ The only mechanistic cycle for the acceptorless amine dehydrogenation reaction was proposed by Szymczak et al. ${ }^{[53]}$ More mechanistic information is available for the reverse reaction, the hydrogenation of nitriles, but still, a complete catalytic cycle for all the steps involved in the process is needed. ${ }^{[54-56]}$ Starting from complex $\mathbf{5}$, the first step is the substitution reaction of a chloride by benzyl amine. Complex 6 is the catalyst resting state and is in acid/base equilibrium with the amido complex (I). A second molecule of benzyl amine promotes this equilibrium. Compound (I) is converted into the ruthenium hydride-imine complex (II) by $\beta$-hydride elimination. The attack of a second benzyl amine to complex II generates the imine by-product. This transformation has been proposed for the acceptorless dehydrogenative coupling of amines (transamination). A similar species has been detected by ESI/MS in the dehydrogenative coupling of alcohols. ${ }^{[57]}$ Nitrile ruthenium complex (IV) is proposed based on the catalytic results on which nitrile was used as the solvent, inhibiting the reaction (Table 1 , entry 10). The two hydrogen release steps are the key points of this catalytic cycle. We propose that $\mathrm{H}_{2}$ is released from ruthenium hydride species with either coordinated imine (II) or benzyl amine (IV) ligands, and most probably through dihydrogen species. The proposed mechanism is one of the possible scenarios for the acceptorless dehydrogenation of primary amines. Additional mechanistic data are required to understand all the elementary catalytic steps of the reaction.

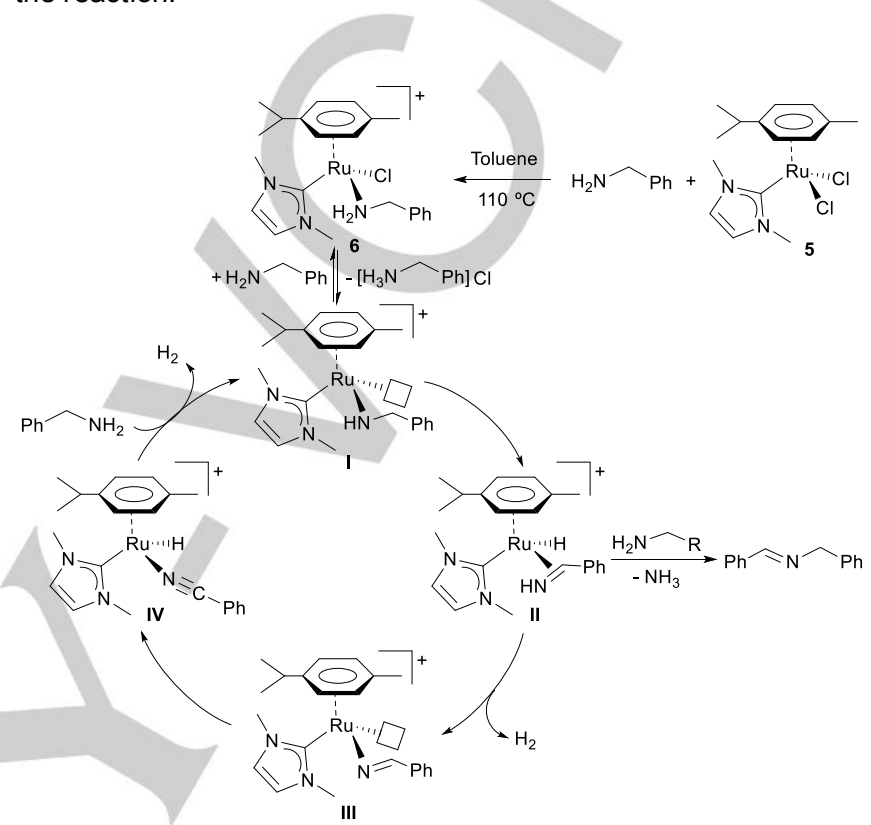

Figure 6. Proposed mechanism for the dehydrogenation of primary amines using $\left[(p\right.$-cym $\left.) \mathrm{Ru}(\mathrm{NHC})(\mathrm{Cl})_{2}\right]$ complexes.

\section{Conclusions}

In this manuscript, we have explored the potential application of the amine/nitrile pair as a liquid organic hydrogen carrier (LOHC). Molecular ruthenium complexes of general formula $[(p-$ $\mathrm{cym}) \mathrm{Ru}(\mathrm{NHC})(\mathrm{Cl})_{2}$ ] are active in the dehydrogenation of primary amines to nitriles with the simultaneous formation of two moles of molecular hydrogen. The reaction proceeds without any external additive under mild reaction conditions. Both catalyst activation and product formation are temperature dependent. The acceptorless dehydrogenation of primary amines is a nonspontaneous process. Hydrogen removal from the reaction medium is required for effective nitrile formation. Mechanistic investigations have shown that the catalyst is activated by chloride/amine substitution. We have observed that the catalyst resting state contains a coordinated benzyl amine. We have assessed the catalytic properties of an analogous ruthenium complex supported on the surface of graphene in the dehydrogenation of benzyl amine. The results are promising as the catalytic system can be recycled up to ten times without significant loss of activity. The main challenge in the dehydrogenation of benzyl-amines is the control of the selectivity. Development of industrial applications in the field of hydrogen storage requires that the transamination reaction that leads to 
imine formation should be suppressed. We have achieved selectivity control using long-chain aliphatic amines. The nitrile species is the sole product. Although the gravimetric percentage of hydrogen content in primary amines is not high compared to other systems, the versatility of amine type compounds and their easy access makes the amine/nitrile pair a potential candidate for LOHCs. In addition, the reverse process, nitrile hydrogenation, is a well stablished reaction and very active and effective catalysts have been described in this regard. Future research in the field is needed, in particular to develop industry-compatible catalysts, but the preliminary results shown here are very encouraging.

\section{Experimental Section}

General Procedures. Anhydrous solvents were obtained using a solvent purification system (SPS M BRAUN) or purchased from commercial suppliers and degassed prior to use by purging with dry nitrogen and keeping over molecular sieves. All other reagents were used as received from commercial suppliers. The imidazolium salts 1,3-bis( $n$-butyl) imidazolium iodide (1a), ${ }^{[58]}$ 4,5-dimethyl-1,3-bis( $n$-butyl) imidazolium chloride (1b), ${ }^{[59]}$ 4,5-dichloro-1,3-bis ( $n$-butyl) imidazolium iodide (1c), ${ }^{60}$ $\left[\mathrm{RuCl}_{2}(p \text {-cymene })\right]_{2},{ }^{[61]}$ and complexes $\mathbf{2 a},{ }^{[62]} \mathbf{3},{ }^{[45]}$ and $\mathbf{5}^{[63]}$ were obtained according to published methods.

NMR spectra were recorded on Varian Innova spectrometers operating at 300 or $500 \mathrm{MHz}\left({ }^{1} \mathrm{H} \mathrm{NMR}\right)$ and 75 or $125 \mathrm{MHz}\left({ }^{13} \mathrm{C} \mathrm{NMR}\right)$. Electrospray mass spectra (ESI-MS) were recorded on a Micromass Quatro LC instrument, and nitrogen was employed as the drying and nebulizing gas. High resolution mass spectra were obtained in a QTOF I (quadrupolehexapole-TOF) mass spectrometer with an orthogonal Z-sprayelectrospray interface (Micromass, Manchester, UK). The drying and nebulizing gas was nitrogen at a flow of $400 \mathrm{~L} / \mathrm{h}$ and $80 \mathrm{~L} / \mathrm{h}$, respectively. The temperature of the source block was set to $120^{\circ} \mathrm{C}$ and the desolvation temperature to $150{ }^{\circ} \mathrm{C}$. A capillary voltage of $3.5 \mathrm{KV}$ was used in the positive scan mode and the cone voltage was set to $30 \mathrm{~V}$. The mass calibration was performed using a solution of sodium iodide in isopropanol/water (50:50) from m/z 150 to 1000 a.m.u. Sample solutions (ca. $1 \times 10^{-4} \mathrm{M}$ ) were infused via syringe pump directly connected to the interface at a flow of $10 \mu \mathrm{l} / \mathrm{min}$. A $1 \mu \mathrm{g} / \mathrm{mL}$ solution of 3,5-diiodo-L-tyrosine was used as the lock mass. Hydrogen analysis was carried out by gas chromatography (GS-MOL 15 meters, column ID $0.55 \mathrm{~mm}$, TCD from J\&W Scientific)

Crystal structure determination. Single crystals of complex 6 were mounted on a polymer tip in a random orientation. Data collection was performed on a SuperNova dual source equipped with a CCD Atlas detector diffractometer. The structure was solved using Olex ${ }^{[64]}$ with the SIR2004[65] structure solution program using Direct Methods and refined with the ShelXL ${ }^{[66]}$ refinement package using Least Squares minimization. Crystal data: orthorhombic, space group Pna21 (no. 33), a = 13.5393(8) A, $\mathrm{b}=16.4138(11) \AA, c=11.4752(8) \AA, V=2550.1(3) \AA^{3}, \mathrm{Z}=4, \mathrm{~T}=$ $200.00(14) \mathrm{K}, \mu($ MoKa $)=0.765 \mathrm{~mm}^{-1}$, Dcalc $=1.497 \mathrm{~g} / \mathrm{cm}^{3}, 13725$ reflections measured $\left(5.804^{\circ} \leq 2 \Theta \leq 51.98^{\circ}\right), 4498$ unique (Rint $=0.0679$, Rsigma $=0.0628)$ which were used in all calculations. The final R1 was $0.0448(\mathrm{I}>2 \sigma(\mathrm{I}))$ and $w R 2$ was 0.1140 (all data).

Synthesis of $2 \mathrm{~b}$ : Silver oxide $(126 \mathrm{mg}, 0.54 \mathrm{mmol})$ was added to a solution of 4,5-dimethyl-1,3-bis(butyl)imidazolium chloride (1b) (178 mg, 0.73 $\mathrm{mmol}$ ) in $\mathrm{CH}_{2} \mathrm{Cl}_{2}$. The mixture was stirred at room temperature overnight and filtered through celite. Then, $\left[\mathrm{Ru}(p \text {-cymene }) \mathrm{Cl}_{2}\right]_{2}(200 \mathrm{mg}, 0.36 \mathrm{mmol})$ was added to the solution and stirred at room temperature overnight. After solvent removal, the crude product was purified by column chromatography. The pure compound $\mathbf{2 b}$ was eluted with dichloromethane/acetone (9:1) and precipitated in a mixture of dichloromethane/hexane to give an orange solid (88 mg, $26.2 \%) .{ }^{1} \mathrm{H}$ NMR $\left(500 \mathrm{MHz} \mathrm{CDCl}_{3}\right) \delta 5.37$ (d, $\left.{ }^{3} \mathrm{~J}=5.9 \mathrm{~Hz}, 2 \mathrm{H}, \mathrm{CH}_{p-c y m}\right), 5.00\left(\mathrm{~d},{ }^{3} \mathrm{~J}=5.9 \mathrm{~Hz}\right.$, $\left.2 \mathrm{H}, \mathrm{CH}_{p-c y m}\right), 4.40\left(\mathrm{~m}, 2 \mathrm{H}, \mathrm{CH}_{2, n-\mathrm{Bu}}\right), 3.98\left(\mathrm{~m}, 2 \mathrm{H}, \mathrm{CH}_{2, n-\mathrm{Bu}}\right), 2.93(\mathrm{~m}, 1 \mathrm{H}$,

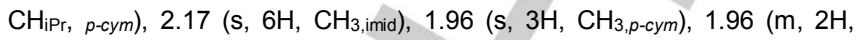

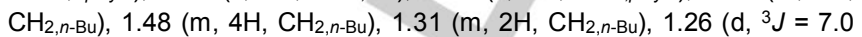

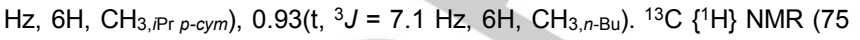
$\left.\mathrm{MHz}, \mathrm{CDCl}_{3}\right): \delta 169.9$ (C $\left.\mathrm{CHC}_{\mathrm{NH}}\right), 126.9\left(\mathrm{C}=\mathrm{C}_{\text {imid }}\right), 107.9\left(\mathrm{C}_{p-c y m}\right), 98.7\left(\mathrm{C}_{p-}\right.$ cym), $85.9\left(\mathrm{C}_{p \text {-cym }}\right), 85.9\left(\mathrm{C}_{p \text {-cym }}\right), 82.3\left(\mathrm{C}_{p \text {-cym }}\right), 82.3\left(\mathrm{C}_{p \text {-cym }}\right), 49.8\left(\mathrm{CH}_{2, n-\mathrm{Bu}}\right)$,

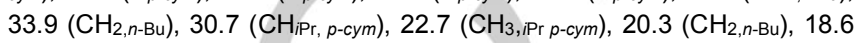
$\left(\mathrm{CH}_{3, p-c y m}\right), 14.0\left(\mathrm{CH}_{3, n-\mathrm{Bu}}\right), 9.8\left(\mathrm{CH}_{3, \text { imid }}\right)$. Electrospray MS (cone $20 \mathrm{~V} ; \mathrm{m} / \mathrm{z}$, fragment): 479.3 [M-Cl] ${ }^{+}$. HRMS ESI-TOF-MS (positive mode): [M-Cl] ${ }^{+}$ monoisotopic peak 479.1770; calc. 479.1770, عr 0 ppm

Synthesis of 2c: The reaction was carried out following the same procedure as the one described for $\mathbf{2 b}$, with 4,5-dichloro-1,3bis(butyl)imidazolium iodide (1c) (138 mg, $0.37 \mathrm{mmol}$ ), and $\mathrm{Ag}_{2} \mathrm{O}$ in $\mathrm{CH}_{2} \mathrm{Cl}_{2}$, and subsequently reacted with $\left[\mathrm{Ru}(p \text {-cymene }) \mathrm{Cl}_{2}\right]_{2}$ (200 $\left.\mathrm{mg}, 0.36 \mathrm{mmol}\right)$ to afford $2 \mathrm{c}$ as an orange solid $(67 \mathrm{mg}, 37.7 \%) .{ }^{1} \mathrm{H} \mathrm{NMR}\left(300 \mathrm{MHz}, \mathrm{CDCl}_{3}\right)$ : $\delta 5.45\left(\mathrm{~d},{ }^{3} \mathrm{~J}=6.0 \mathrm{~Hz}, 2 \mathrm{H}, \mathrm{CH}_{p-c y m}\right), 5.08\left(\mathrm{~d},{ }^{3} \mathrm{~J}=6.0 \mathrm{~Hz}, 2 \mathrm{H}, \mathrm{CH}_{\text {p-cym }}\right), 4.53$

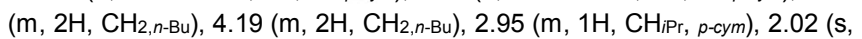
$\left.3 \mathrm{H}, \mathrm{CH}_{3, p-c y m}\right), 2.02\left(\mathrm{~m}, 2 \mathrm{H}, \mathrm{CH}_{2, n-\mathrm{Bu}}\right) 1,74\left(\mathrm{~m}, 2 \mathrm{H}, \mathrm{CH}_{2, n-\mathrm{Bu}}\right), 1.41(\mathrm{~m}, 4 \mathrm{H}$, $\mathrm{CH}_{2, n-\mathrm{Bu}),} 1.29$ (d, ${ }^{3} \mathrm{~J}=6.9 \mathrm{~Hz}, 6 \mathrm{H}, \mathrm{CH}_{3, \operatorname{Pr} p-c y m)}, 0.96\left(\mathrm{t},{ }^{3} \mathrm{~J}=7.3 \mathrm{~Hz}, 6 \mathrm{H}\right.$, $\left.\mathrm{CH}_{3, n-\mathrm{Bu}}\right) \cdot{ }^{13} \mathrm{C}\left\{{ }^{1} \mathrm{H}\right\}$ NMR $\left(75 \mathrm{MHz}, \mathrm{CDCl}_{3}\right): \delta 175.2\left(\mathrm{C}_{\mathrm{NHC}-\mathrm{Ru}}\right), 117.8$ $\left(\mathrm{C}=\mathrm{C}_{\text {imid }}\right), 108.4\left(\mathrm{C}_{p \text {-cym }}\right), 98.9\left(\mathrm{C}_{p-c y m}\right), 86.4\left(\mathrm{C}_{p-c y m}\right), 82.8\left(\mathrm{C}_{p-c y m}\right), 51.4$

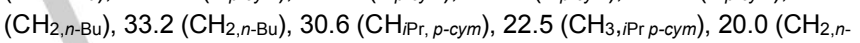
$\mathrm{Bu}$ ), $18.7\left(\mathrm{CH}_{3, p-c y m}\right), 13.7\left(\mathrm{CH}_{3, n-\mathrm{Bu}}\right)$. Electrospray MS (cone $20 \mathrm{~V} ; \mathrm{m} / \mathrm{z}$, fragment): $519.1[\mathrm{M}-\mathrm{Cl}]^{+}$. HRMS ESI-TOF-MS (positive mode): [M-Cl] ${ }^{+}$ monoisotopic peak 519.0671; calc. 519.0672, عr 0.2 ppm.

Synthesis of 6: Complex 5 (10 $\mathrm{mg}, 0.0248 \mathrm{mmol})$ and sodium tetrafluoroborate (26 mg, $0.23 \mathrm{mmol}$ ) were suspended in $3 \mathrm{~mL}$ of dichloromethane and $2 \mathrm{~mL}$ of methanol. The mixture was stirred for 5 minutes. Then, $0.024 \mathrm{mmol}$ of 4-methyl benzyl amine was added and the solution was stirred for 1 hour. After solvent removal, complex 6 was obtained as a pale yellow solid. ${ }^{1} \mathrm{H}$ NMR $\left(500 \mathrm{MHz}, \mathrm{CDCl}_{3}\right) \delta 7.35(\mathrm{~d}, \mathrm{~J}=$ $\left.7.9 \mathrm{~Hz}, 2 \mathrm{H}, \mathrm{CH}_{\text {amine }}\right), 7.17-6.99\left(\mathrm{~m}, 4 \mathrm{H}, \mathrm{CH}_{\text {amine; }} \mathrm{CH}_{\text {imid }}\right.$ ), 5.81 (d, J = 6.0

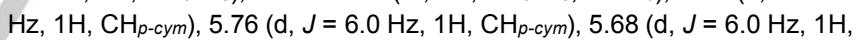
$\left.\mathrm{CH}_{\text {-cym }}\right), 5.45$ (d, J = 6.0 Hz, 1H, $\left.\mathrm{CH}_{\text {-cym }}\right), 4.09\left(\mathrm{~m}, 2 \mathrm{H}, \mathrm{CH}_{2}\right), 3.99(\mathrm{~s}, 3 \mathrm{H}, \mathrm{N}-$ $\left.\mathrm{CH}_{3}\right), 3.75\left(\mathrm{~s}, 3 \mathrm{H}, \mathrm{N}-\mathrm{CH}_{3}\right), 2.84\left(\mathrm{~m}, 1 \mathrm{H}, \mathrm{CH}_{i \mathrm{Pr}, p-c y m}\right), 2.27$ (s, 3H, $\mathrm{CH}_{3}$ amine),

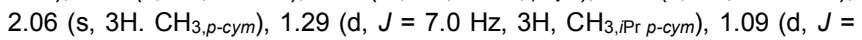

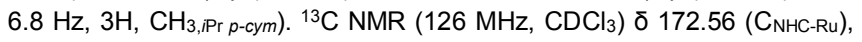
138.03, 136.62, 129.78, 129.11 ( $\left.\mathrm{C}_{\text {amine }}\right), 125.07,124.29\left(\mathrm{CH}_{\text {imidazole }}\right)$, 112.18, $99.96\left(\mathrm{C}_{\mathrm{q}, p-c y m}\right), 85.42,84.18,83.39,82.81\left(\mathrm{CH}_{p-c y m}\right), 53.62(\mathrm{Ph}-$

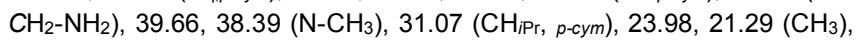
20.89, $18.43\left(\mathrm{CH}_{3, \mathrm{Pr}}\right.$-cym).

Catalytic dehydrogenation reactions: catalytic runs were performed in a round bottom flask using 1 equivalent of amine, $2 \mathrm{~mol} \%$ of catalyst, and $3 \mathrm{~mL}$ of toluene, and heating for a suitable period of time at $110^{\circ} \mathrm{C}$. The yields and conversions were determined by GC analysis using anisole as the internal standard.

Procedure for hydrogen identification. All glassware was carefully cleaned with Milli-Q water and rinsed with acetone prior to use. A $25 \mathrm{~mL}$ round bottom flask was charged with $0.30 \mathrm{mmol}$ of amine, $2 \mathrm{~mol} \%$ of ruthenium catalyst and $2 \mathrm{~mL}$ of toluene and heated at $110^{\circ} \mathrm{C}$. At selected times (ca. $50 \%$ conversion), a $1.5 \mathrm{~mL}$ sample of the generated gas was collected and the hydrogen content was qualitative analyzed by gas chromatography (GS-MOL 15 meters, column ID $0.55 \mathrm{~mm}$, TCD from J\&W Scientific). 


\section{Acknowledgements}

The authors thank the financial support from MINECO (CTQ201569153-C2-2-R), Generalitat Valenciana (AICO/2015/039), and Universitat Jaume I (P1.1B2015-09). The authors are very grateful to the 'Serveis Centrals d'Instrumentació Científica (SCIC)' of the Universitat Jaume I.

Keywords: Hydrogen storage • LOHC • Supported catalysis • Acceptorless amine dehydrogenation $•$ Nitrile synthesis

[1] M. Ball, M. Weeda, Compendium of Hydrogen Energy, Elsevier, 2016

[2] V. Blagojević, D. Minić, J. G. Novaković, D. Minić, Hydrog. Energy Challenges Perspect. 2012, 3-28.

[3] A. Midilli, M. Ay, I. Dincer, M. A. Rosen, Renew. Sustain. Energy Rev. 2005, 9, 255-271.

[4] N. Armaroli, V. Balzani, Energy for a Sustainable World: From the Oil Age to a Sun-Powered Future, Wiley-VCH, 2010.

[5] A. Zuttel, A. Remhof, A. Borgschulte, O. Friedrichs, Philos. Trans. R. Soc. A Math. Phys. Eng. Sci. 2010, 368, 3329-3342.

[6] L. Jörissen, Green Energy Technol. 2012, 45, 189-203.

[7] A. F. Dalebrook, W. Gan, M. Grasemann, S. Moret, G. Laurenczy, Chem. Commun. 2013, 49, 8735

[8] P. Jena, J. Phys. Chem. Lett. 2011, 2, 206-211.

[9] S. Sahler, M. H. G. Prechtl, Chem CatChem 2011, 3, 1257-1259.

[10] A. J. Esswein, D. G. Nocera, Chem. Rev. 2007, 107, 4022-4047.

[11] J. D. Holladay, J. Hu, D. L. King, Y. Wang, Catal. Today 2009, 139, 244 260.

[12] M. H. G. Prechtl, S. Sahler, Curr. Org. Chem. 2013, 17, 220-228.

[13] S. Satyapal, J. Petrovic, C. Read, G. Thomas, G. Ordaz, Catal. Today 2007, 120, 246-256

[14] R. K. Ahluwalia, X. Wang, J. Power Sources 2008, 177, 167-176.

[15] K. Müller, W. Arlt, in Renew. Energy Econ. Emerg. Technol. Glob. Pract., Nova Science Publishers, Inc., 2013, pp. 45-60.

[16] U. Eberle, M. Felderhoff, F. Schüth, Angew. Chemie Int. Ed. 2009, 48, 6608-6630.

[17] R. H. Crabtree, Energy Environ. Sci. 2008, 1, 134

[18] O. R. Luca, T. Wang, S. J. Konezny, V. S. Batista, R. H. Crabtree, New J. Chem. 2011, 35, 998.

[19] E. Clot, O. Eisenstein, R. H. Crabtree, Chem. Commun. 2007, 22312233.

[20] M. Markiewicz, Y. Q. Zhang, A. Bosmann, N. Bruckner, J. Thoming, P. Wasserscheid, S. Stolte, Energy Environ. Sci. 2015, 8, 1035-1045.

[21] T. He, Q. Pei, P. Chen, J. Energy Chem. 2015, 24, 587-594.

[22] M. Yadav, Q. Xu, Energy Environ. Sci. 2012, 5, 9698.

[23] P. Hu, Y. Ben-David, D. Milstein, Angew. Chemie Int. Ed. 2016, 55, 1061-1064.

[24] P. Hu, E. Fogler, Y. Diskin-Posner, M. A. Iron, D. Milstein, Nat. Commun 2015, 6, 6859.

[25] D. Teichmann, K. Stark, K. Mueller, G. Zoettl, P. Wasserscheid, W. Arlt K. Müller, G. Zöttl, P. Wasserscheid, W. Arlt, Energy Environ. Sci. 2012 $5,9044$.

[26] D. Teichmann, W. Arlt, P. Wasserscheid, R. Freymann, Energy Environ. Sci. 2011, 4, 2767
[27] P. J. Bonitatibus, S. Chakraborty, M. D. Doherty, O. Siclovan, W. D Jones, G. L. Soloveichik, Proc. Natl. Acad. Sci. 2015, 112, 1687-1692.

[28] M. Grellier, S. Sabo-Etienne, Dalt. Trans. 2014, 43, 6283.

[29] K.-N. T. Tseng, A. M. Rizzi, N. K. Szymczak, J. Am. Chem. Soc. 2013 135, 16352-16355.

[30] F. Gould, G. Johnson, A. Ferris, J. Org. Chem. 1960, 25, 1658-1660.

[31] S. Gomez, J. A. Peters, T. Maschmeyer, Adv. Synth. Catal. 2002, 344, 1037-1057.

[32] C. de Bellefon, P. Fouilloux, Catal. Rev. 2006, 36, 459-506.

[33] S. Werkmeister, K. Junge, M. Beller, Org. Process Res. Dev. 2014, 18 , 289-302.

[34] D. B. Bagal, B. M. Bhanage, Adv. Synth. Catal. 2015, 357, 883-900.

[35] A. Mukherjee, D. Srimani, S. Chakraborty, Y. Ben-David, D. Milstein, J. Am. Chem. Soc. 2015, 137, 8888-8891.

[36] H. T. Clarke, R. R. Read, J. Am. Chem. Soc. 1924, 46, 1001-1003.

[37] C. F. Koelsch, A. G. Whitney, J. Org. Chem. 1941, 6, 795-803.

[38] G. C. Vougioukalakis, R. H. Grubbs, Chem. Rev. 2010, 110, 1746-1787.

[39] E. Colacino, J. Martinez, F. Lamaty, Coord. Chem. Rev. 2007, 251, 726764.

[40] C. Samojłowicz, M. Bieniek, K. Grela, Chem. Rev. 2009, 109, 3708-3742.

[41] K. M. Kuhn, J.-B. Bourg, C. K. Chung, S. C. Virgil, R. H. Grubbs, J. Am. Chem. Soc. 2009, 131, 5313-5320

[42] T. Dröge, F. Glorius, Angew. Chemie Int. Ed. 2010, 49, 6940-6952.

[43] S. Díez-González, S. P. Nolan, Coord. Chem. Rev. 2007, 251, 874-883.

[44] A. Prades, E. Peris, M. Albrecht, Organometallics 2011, 30, 1162-1167. S. Sabater, J. A. Mata, E. Peris, ACS Catal. 2014, 4, 2038-2047. S. Sabater, J. A. Mata, E. Peris, Organometallics 2015, 34, 1186-1190.

47] A. Primo, M. Puche, O. D. Pavel, B. Cojocaru, A. Tirsoaga, V. Parvulescu, H. García, Chem. Commun. 2016, 52, 1839-1842.

[48] J. Albero, H. Garcia, J. Mol. Catal. A Chem. 2015, 408, 296-309.

[49] B. F. Machado, P. Serp, Catal. Sci. Technol. 2012, 2, 54-75.

[50] M. R. Axet, O. Dechy-Cabaret, J. Durand, M. Gouygou, P. Serp, Coord. Chem. Rev. 2016, 308, 236-345.

[51] P. Csabai, F. Joó, Organometallics 2004, 23, 5640-5643.

[52] W. H. Bernskoetter, M. Brookhart, Organometallics 2008, 27, 2036-2045.

[53] K.-N. Tseng, N. Szymczak, Synlett 2014, 25, 2385-2389.

[54] R. Reguillo, M. Grellier, N. Vautravers, L. Vendier, S. Sabo-Etienne, J. Am. Chem. Soc. 2010, 132, 7854-5.

[55] R. V Jagadeesh, H. Junge, M. Beller, Nat. Commun. 2014, 5, 1-8.

[56] S. E. Clapham, A. Hadzovic, R. H. Morris, Coord. Chem. Rev. 2004, 248 , 2201-2237.

[57] C. Vicent, D. G. Gusev, ACS Catal. 2016, 6, 3301-3309.

[58] I. Dinarès, C. Garcia de Miguel, A. Ibáñez, N. Mesquida, E. Alcalde Green Chem. 2009, 11, 1507.

[59] G. Mlostoń, J. Romański, M. Jasiński, H. Heimgartner, Tetrahedron Asymmetry 2009, 20, 1073-1080.

[60] R. Corberán, M. Sanaú, E. Peris, J. Am. Chem. Soc. 2006, 128, 39743979.

[61] M. A. Bennett, A. K. Smith, J. Chem. Soc., Dalton Trans. 1974, 233.

[62] L. Mercs, A. Neels, M. Albrecht, Dalton Trans. 2008, 3, 5570-5576.

[63] W. A. Herrmann, M. Elison, J. Fischer, C. Köcher, G. R. J. Artus, Chem Eur. J. 1996, 2, 772-780.

[64] O. V. Dolomanov, L. J. Bourhis, R. J. Gildea, J. A. K. Howard, H. Puschmann, J. Appl. Crystallogr. 2009, 42, 339-341.

[65] M. C. Burla, R. Caliandro, M. Camalli, B. Carrozzini, G. L. Cascarano, L. De Caro, C. Giacovazzo, G. Polidori, D. Siliqi, R. Spagna, J. Appl. Crystallogr. 2007, 40, 609-613.

[66] G. M. Sheldrick, Acta Crystallogr. Sect. A, Found. Adv. 2015, 71, 3-8. 


\section{Entry for the Table of Contents}

\section{FULL PAPER}

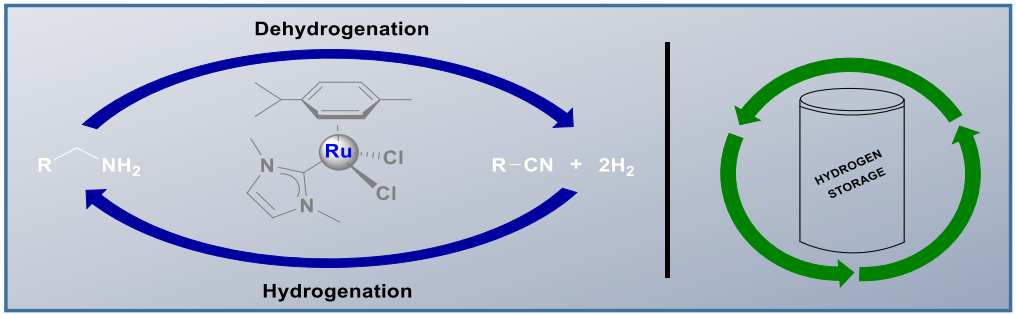

David Ventura-Espinosa, Aida MarzáBeltrán and Jose A. Mata*

Page No. - Page No.

Catalytic hydrogen production by ruthenium complexes from the conversion of primary amines to nitriles: Potential application as liquid organic hydrogen carrier 